\title{
THE STANDARD CHARTER OF A MUNICIPALITY AS A MEANS OF LEGAL TECHNIQUE
}

\author{
Irina A. Kareva \\ Volgograd Conservatory (Institute) named after P.A. Serebryakov, Volgograd, Russian Federation
}

\begin{abstract}
Introduction: the constitutional changes open a new round of scientific discussion about the place of municipal power in the system of separation of powers. Municipalities are experiencing a shortage of resources. Despite this, they are responsible for the development and adoption of statutes. The work is based on the hypothesis that the use of standard charters allows for more efficient use of the resources of municipalities and the improvement of the quality of the legal text. Purpose: to determine the possibility and necessity of using standard charters of municipalities. Tasks: to establish a link between the resources of a municipality and the effectiveness of its lawmaking; to analyze the examples of standard charters of municipalities; to predict the effect of the application of standard charters; to develop a roadmap for the implementation of standard charters. Methods: analysis, comparative law, predictive, statistical. Results: law-making is very burdensome for small municipalities, and the existing easing is insufficient. In foreign legislation, Russian and foreign practice, standard charters are used to save the resources of municipalities. The mechanism of standard charters has signs of smart regulation. There are two types of standard documents: template documents and model documents (actually standard documents). Conclusions: a comparison of the resources of the municipality with the scope of its rights and obligations revealed an imbalance in the legal regulation of municipal law-making. The model charters of municipalities allow us to solve this problem to some extent. We have proposed concrete steps for the legislative implementation of the legal mechanism of model charters in the digital economy. The analysis of the results of this project may confirm or refute the nature of the model statutes as a manifestation of smart regulation. In the course of the research, the author concluded that the topic of standard documents is not sufficiently studied in the science of legal technology. To eliminate this gap, it is necessary to define the concept and features of standard documents, their place among the tools of legal technology. The study of model documents is particularly important in the light of the upcoming spread of machinereadable law.
\end{abstract}

Key words: charter of a municipality, standard document, draft legal act, document templates, legal technique, municipal law-making, smart regulation.

Citation. Kareva I.A. The Standard Charter of a Municipality As a Means of Legal Technique. Legal Concept $=$ Pravovaya paradigma, 2021, vol. 20, no. 3, pp. 94-99. (in Russian). DOI: https://doi.org/10.15688/lc.jvolsu.2021.3.15

УДК 340.113.2:342.553

Дата поступления статьи: 11.05.2021

ББК 67.400 .7

Дата принятия статьи: 14.06.2021

\section{ТИПОВОЙ УСТАВ МУНИЦИПАЛЬНОГО ОБРАЗОВАНИЯ КАК СРЕДСТВО ЮРИДИЧЕСКОЙ ТЕХНИКИ}

\author{
Ирина Александровна Карева \\ Волгоградская консерватория (институт) им. П.А. Серебрякова, г. Волгоград, Российская Федерация
}

Введение: конституционные изменения открывают новый раунд научной дискуссии о месте муниципальной власти в системе разделения властей. Муниципальные образования испытывают дефицит ресурсов. Несмотря на это, на них возлагается обязанность по разработке и принятию уставов. В основе работы лежит гипотеза о том, что применение типовых уставов позволяет эффективнее использовать ресурсы муниципальных образований и повысить качество правового текста. Цель: определить возможность и необходимость использования типовых уставов муниципальных образований. Задачи: установить 
связь между ресурсами муниципального образования и эффективностью его правотворчества; проанализировать примеры типовых уставов муниципальных образований; спрогнозировать эффект от применения типовых уставов; разработать дорожную карту внедрения типовых уставов. Методы: анализ, сравнительно-правовой, прогностический, статистический. Результаты: правотворчество очень обременительно для небольших муниципальных образований, а существующие послабления недостаточны. В зарубежном законодательстве, российской и зарубежной практике для экономии ресурсов муниципальных образований используют типовые уставы. Механизм типовых уставов имеет признаки «умного регулирования». Существует два вида типовых документов: шаблонные и модельные (собственно типовые). Выводы: сопоставление ресурсов муниципального образования с объемом его прав и обязанностей выявило несбалансированность правового регулирования в части муниципального правотворчества. Типовые уставы муниципальных образований позволяют в некоторой степени решить эту проблему. Мы предложили конкретные шаги по законодательной реализации правового механизма типовых уставов в рамках цифровой экономики. Анализ результатов этого проекта может подтвердить или опровергнуть характер типовых уставов как проявление «умного регулирования». В процессе исследования мы пришли к выводу о том, что в науке юридической техники недостаточно изучена тема типовых документов. Для устранения этого пробела необходимо определить понятие и признаки типовых документов, их место среди инструментов юридической техники. Исследование типовых документов представляется особенно важным в свете грядущего распространения машиночитаемого права.

Ключевые слова: устав муниципального образования, типовой документ, проект правового акта, шаблоны документов, юридическая техника, муниципальное правотворчество, умное регулирование.

Цитирование. Карева И. А. Типовой устав муниципального образования как средство юридической техники // Legal Concept = Правовая парадигма. - 2021. - T. 20, № 3. - C.94-99. - DOI: https://doi.org/10.15688/lc.jvolsu.2021.3.15

\section{Введение}

Среди изменений, которые были внесены в 2020 г. в Конституцию Российской Федерации, есть и те, что затрагивают нормы о местном самоуправлении. Так, ст. 132 была дополнена ч. 3 , в которой говорится о том, что органы местного самоуправления и органы государственной власти входят в единую систему публичной власти в Российской Федерации и осуществляют взаимодействие для наиболее эффективного решения задач в интересах населения, проживающего на соответствующей территории.

В науке высказываются различные мнения относительно правовых и политических последствий принятых поправок: от восприятия их как неизбежного этапа на пути совершенствования правовой системы Российского государства и окончательного определения места муниципальной власти [2, с. 32] до опасений относительно снижения роли местного самоуправления [7, с. 81]. Оценка принятых изменений выходит за рамки настоящей статьи. С уверенностью можно заявить лишь о том, что для реализации положений обновленной конституции будут внесены поправки и в ФЗ «Об общих принципах организации местного самоуправления в РФ» (далее - закон о МСУ).
В ожидании предстоящей муниципальной реформы мы, пользуясь таким случаем, предлагаем законодательно закрепить существующую практику использования типовых уставов муниципальных образований (далее МO). Это позволит не только укрепить единство системы публичной власти, но и решить ряд других насущных проблем, которые стоят перед муниципальной властью. Более того, в статье мы покажем, что использование типового устава как особого вида юридической конструкции позволит создать задел для ответа на те вопросы, которые встанут перед юридической наукой в ближайшем будущем.

\section{Ресурсоемкость}

\section{муниципального правотворчества}

Поселения являются самым распространенным видом МО. Средняя численность населения в поселениях Волгоградской области составляет 1141 человек. При этом их бюджеты крайне ограничены, собственных доходов зачастую не хватает на содержание органов местного самоуправления. Даже федеральный законодатель при лучшем финансировании и кадровом обеспечении не может гарантировать стабильно высокое качество законов. 


\section{ТЕОРИЯ И ПРАКТИКА ГОСУДАРСТВЕННО-ПРАВОВОГО РАЗВИТИЯ}

Одним из способов «сглаживания» неравенства муниципалитетов является прямая зависимость объема прав и обязанностей от финансов [8, с. 20]. У крупных и более обеспеченных МО шире круг полномочий, сложная система органов и больше муниципальных правовых актов. У поселений небольшой перечень вопросов местного значения, причем у сельских меньше, чем у городских. В некоторых случаях они могут создавать упрощенную систему органов: с совмещением должностей главы МО, главы администрации и председателя представительного органа; без администрации и представительного органа. На них не распространяются требования о проведении экспертизы и оценки регулирующего воздействия муниципальных правовых актов.

Последнее наиболее интересно для нашего исследования, поскольку таким образом законодатель уменьшил объем обязанностей в сфере муниципального правотворчества. Однако изъятие представляется недостаточным в свете принципа пропорциональности прав и обязанностей субъекта права имеющимся в его распоряжении ресурсам. Речь идет об уставе, который каждое МО вне зависимости от количества жителей и размера бюджета обязано разработать, принять и поддерживать в актуальном состоянии. Требования, предъявляемые к уставам, не дифференцируются в зависимости от вида МО. Это, например, затрудняет реализацию структуры органов местного самоуправления в поселениях без представительного органа. В этом случае устав должен быть принят населением на сходе. Но отсутствие представительного органа означает и отсутствие аппарата, который мог бы подготовить проект устава. Получается, что такой учредительный документ жители должны подготовить самостоятельно. О нежизнеспособности подобной модели говорит и тот факт, что в Волгоградской области, например, нет ни одного поселения, где функции представительного органа осуществляет сход граждан, хотя право на это имеют семь муниципалитетов. Вместо этого проводится политика укрупнения сельских поселений либо объединения их в городской округ.

Часто меняется и само законодательство, появляются новые требования к уставу.
МО должны осуществлять постоянный мониторинг подобных изменений и периодически вносить «технические» изменения.

Наконец, сам устав и изменения в нем подлежат государственной регистрации в Минюсте. Обнаруженные на этапе регистрации ошибки могут стать основанием для отказа в регистрации. Это также требует дополнительных действий со стороны уполномоченных органов МO.

\section{Российский и зарубежный опыт использования типовых уставов}

Поскольку вопрос несоответствия ресурсов МО и возложенных на него обязанностей в сфере муниципального правотворчества не был снят законодателем, его решение осуществляется на уровне юридической практики.

Здесь находит подтверждение наша гипотеза о востребованности типовых уставов МO - в ряде регионов есть опыт создания таких документов на надмуниципальном уровне следующими субъектами: 1) территориальными органами Минюста; 2) органами исполнительной власти субъектов РФ; 3) советами МО субъектов РФ; 4) научным сообществом.

Об этом свидетельствует и международный опыт.

Типовые уставы МО утверждены в Киргизии на государственном уровне [4], на Украине их разрабатывает и публикует при поддержке государства некоммерческая организация [5, с. 9-26].

Некоммерческие организации США также участвуют в разработке модельных уставов [11, p. 35-36]. Описания готовых организационных моделей муниципалитетов закреплены в законах. Но поскольку местное самоуправление является правом, а не обязанностью населения, то в городах без уставов местные органы создаются и функционируют в соответствии с законом штата [10, p. 2], то есть по установленной модели.

Законодательство Белоруссии вообще не предусматривает наличие муниципального устава - все положения императивным образом определены в законе [3], что похоже на подход США.

Типовые уставы как средство юридической техники применяются в администра- 
тивном и гражданском праве России. Общества с ограниченной ответственностью могут вести деятельность на основании типовых уставов.

Таким образом, использование типовых уставов МО обосновано с точки зрения международного опыта, по аналогии с другими отраслями российского права и практикой муниципального права.

Для типовых уставов характерны проявления таких признаков «умного регулирования», как осуществление воздействия на разных уровнях, привлечение суррогатных регуляторов, поиск наиболее оптимальной формы, направленность на экономию средств [9, p. 1296-1297].

\section{Проблемы}

\section{законодательного закрепления типовых уставов МО}

В федеральном законодательстве требования к уставам МО закреплены настолько подробно, что большинство из них копируют соответствующие нормы закона и различаются только по названиям [6, с. 3, 16-17]. Реализация конституционных поправок оставит, на наш взгляд, еще меньше простора для муниципального правотворчества. Это можно и нужно использовать для того, чтобы перенаправить ресурсы с выполнения формальных обязанностей на решение насущных вопросов местного значения.

Анализ приведенных примеров позволяет сделать вывод о том, что есть две формы существования данного правового явления.

Во-первых, это шаблонные уставы, то есть примеры, образцы, на основании которых МО должны самостоятельно принять текст собственного устава, максимально приближенный к шаблону.

Во-вторых, собственно типовые или модельные уставы, положения которого определены в виде законченного юридического текста и могут быть приняты только в целом.

Представляется, что необходимо стремиться к использованию второй формы, поскольку она минимизирует количество действий по принятию устава для МО. Но это требует более тщательной проработки самой концепции. Так, обязанность осуществления правотворческой деятельности делегируется на федеральный уровень.

В самом общем виде стратегия реализации инициативы состоит из следующих шагов:

1. Дополнить ст. 44 закона о МСУ нормой о том, что МО может принимать устав в форме типового устава, утвержденного уполномоченным органом.

2. Сформулировать конкретные варианты структуры и порядка формирования органов местного самоуправления, исходя из возможных в соответствии с законом.

3. Изменить государственный реестр уставов МО таким образом, чтобы он в явном виде отражал сведения, подлежащие определению уставом, но которые не могут быть включены в текст типового устава (наименование муниципалитета, количество депутатов и др.).

4. Предусмотреть необходимость существования типовых уставов в машиночитаемой форме. Это необходимое условие «умного регулирования» [1, с. 158-159] позволит создавать, обрабатывать и просматривать документы как в текстовом виде для восприятия человеком, так и в виде, распознаваемом компьютерными программами.

5. Определить орган, ответственный за утверждение типовых уставов - Минюст. Разработка типовых уставов должна происходить при участии представителей науки и практических работников.

В случае, если опыт использования типовых уставов будет признан успешным, можно распространить его и на некоторые другие муниципальные правовые акты: а) к которым предъявляются повышенные формальные требования; б) которые требуют периодического принятия либо частого внесения изменений и дополнений (о внесении изменений и дополнений в устав, о бюджете, о налогах и сборах).

\section{Выводы}

Возможность законодательного закрепления типовых уставов МО в Российской Федерации представляется волне обоснованной как с научной, так и с практической точки зрения.

Учитывая комплексный характер муниципального права, реализация настоящей ини- 
циативы будет способствовать достижению нескольких целей в различных сферах общественной жизни. С конституционно-правовой точки зрения это поможет интеграции местного самоуправления в систему единой публичной власти. С экономической - такая реформа должна увеличить эффективность использования ограниченных ресурсов МО. Повысится качество муниципальных правовых актов с точки зрения юридической техники. Наконец, эксперимент с созданием правовых актов в машиночитаемой форме полностью вписывается в рамки национального проекта «Цифровая экономика». Типизация права, то есть стандартизация его формы в той мере, которая позволяет стать объектом обработки с помощью технических средств, не теряя при этом свойства регулятора общественных отношений, открывает путь к действительно «умному регулированию».

\section{СПИСОК ЛИТЕРАТУРЫ}

1. Ковалева, Н. Н. Машиночитаемое право как механизм умного регулирования в области связи / Н. Н. Ковалева // Правовая политика и правовая жизнь. - 2019. - № 3. - С. 158-159.

2. Мухлынина, М. М. Система публичной власти и вопросы местного самоуправления в свете поправки 2020 года к Конституции Российской Федерации / М. М. Мухлынина // Государственная служба и кадры. - 2020. - № 2. - С. 30-33. - DOI: 10.24411/2312-0444-2020-10055.

3. О местном управлении и самоуправлении в Республике Беларусь : Закон Республики Беларусь от 4 января 2010 г. № 108-3 // Национальный правовой Интернет-портал Республики Беларусь. - Электрон. текстовые дан. - Режим доступа: https:// pravo.by/document/?guid=3871\&p0=h11000108 (дата обращения: 22.04.2021). - Загл. с экрана.

4. Об утверждении Типового устава местного сообщества (айылного аймака) : Приказ Государственного агентства по делам местного самоуправления и межэтнических отношений при правительстве Киргизской Республики от 28 мая 2020 г. № 01-18/48 // Институт политики развития. - Электрон. текстовые дан. - Режим доступа: http://dpi.kg/ upload/file/Prikaz_GAMSUMO_N01-18-48_ot_ 28052020_Ob_utverjdenii_Tipovogo_ustava_mestnyh_ soobshestv_RUS.pdf(дата обращения: 22.04.2021). Загл. с экрана.

5. Типовий статут територіальної громади / В. Козіна [та ін.] ; Ассоціація міст України. -3-є вид. -
Київ, 2020. - 68 с. - Электрон. текстовые дан. - Режим доступа: http://auc.org.ua/sites/default/files/ library/modul_1.pdf (дата обращения: 22.04.2021).Загл. с экрана.

6. Чермит, А. Ю. Устав муниципального образования в системе нормативно-правового регулирования местного самоуправления : автореф. дис. ... канд. юрид. наук / Чермит Асиет Юрьевна ; Краснодарский ун-т МВД России. - Владикавказ, 2011. $-22 \mathrm{c}$.

7. Чихладзе, Л. Т. Местное самоуправление в правовых позициях Конституционного Суда РФ и его судей в контексте конституционной реформы2020 / Л. Т. Чихладзе, О. В. Болдырев // Антиномии. 2020. - T. 20 - № 3. - C. 71-87. - DOI: 10.24411/26867206-2020-10304.

8. Шугрина, Е. С. Особенности правового статуса разных видов муниципальных образований / Е. С. Шугрина // Lex Russica. - 2017. - № 2 (123). DOI: 10.17803/1729-5920.2017.123.2.017-025.

9. Davydova, M. L. Smart Technologies in Lawmaking: Towards the Concept of Smart Regulation / M. L. Davydova, V. O. Makarov // Lecture Notes in Networks and System. - Vol. 155. - P. 1296-1305. DOI: 10.1007/978-3-030-59126-7_142.

10. Deslatte, A. Municipal Charters / A. Deslatte // Encyclopedia of Public Administration and Public Policy / ed. by A. Domonic [et al.]. - [S. 1.] : Taylor \& Francis Group, 2015. - 4196 p.

11. Svara, J. Revising the Model City Charter: The Case for Change / J. Svara // National Civic Review. 2020. - Vol. 109, № 3. - P. 35-45. - Electronic text data. Mode of access: https://www.jstor.org/stable/10.32543/ naticivirevi.109.3.0035 (date of access: 22.04.2021). Title from screen.

\section{REFERENCES}

1. Kovaleva N.N. Mashinochitayemoye pravo kak mekhanizm umnogo regulirovaniya $v$ oblasti svyazi [Machine-Readable Law As a Mechanism of Smart Regulation in the Field of Communication]. Pravovaya politika i pravovaya zhizn' [Legal Policy and Legal Life], 2019, no. 3, pp. 158-159.

2. Muhlynina M.M. Sistema publichnoj vlasti i voprosy mestnogo samoupravleniya $\mathrm{v}$ svete popravki 2020 goda k Konstitucii Rossijskoj Federacii [The System of Public Power and Issues of Local SelfGovernment in the Light of the 2020 Amendment to the Constitution of the Russian Federation]. Gosudarstvennaya sluzhba i kadry [Civil Service and Personnel], 2020, no. 2, pp. 30-33. DOI: 10.24411/23120444-2020-10055.

3. Zakon Respubliki Belarus' ot 4 yanvarya $2010 \mathrm{~g}$. No. 108-Z "O mestnom upravlenii i samoupravlenii v 
Respublike Belarus"' [Law No. 108-Z on Local Government in the Republic Dated Belarus of January 4, 2010]. Nacional'nyj pravovoj Internet-portal Respubliki Belarus' [National Legal Internet Portal of the Republic of Belarus]. URL: https://pravo.by/ document/?guid $=3871 \& \mathrm{p} 0=\mathrm{h} 11000108$ (accessed 22 April 2021).

4. Prikaz Gosudarstvennogo agentstva po delam mestnogo samoupravleniya i mezhe'tnicheskikh otnoshenij pri pravitel'stve Kirgizskoj Respubliki ot 28 maya 2020 g. No. 01-18/48 "Ob utverzhdenii Tipovogo ustava mestnogo soobshhestva (ajylnogo ajmaka)" [Order of the State Agency for Local SelfGovernment and Inter-Ethnic Relations Under the Government of the Kyrgyz Republic No. 01-18/48 on Approval of the Model Charter of the Local Community (ayil aimak) Dated May 28, 2020]. Institut politiki razvitiya [Development Policy Institute]. URL: http://dpi.kg/upload/file/Prikaz_GAMSUMO_N01-1848 ot 28052020_Ob_utverjdenii_Tipovogo_ustava mestnyh_soobshestv_RUS.pdf (accessed 22 April 2021).

5. Chermit A.Yu. Ustav municipal'nogo obrazovaniya $v$ sisteme normativno-pravovogo regulirovaniya mestnogo samoupravleniya: dis. ... kand. jurid. nauk. [A Municipality Charter in the System of Local Self-Government Legal Regulation. Cand. yurid. sci. abs. diss.]. Vladikavkaz, 2015. 22 p.

6. Chikhladze L.T., Boldyrev O.Yu. Mestnoe samoupravlenie $\mathrm{v}$ pravovykh pozitsiyakh
Konstitutsionnogo Suda RF i ego sudey v kontekste konstitutsionnoy reformy-2020 [Local SelfGovernment in Legal Positions of the Constitutional Court of the Russian Federation and its Judges in the Context of Constitutional reform 2020]. Antinomii [Antinomies], 2020, vol. 20, iss. 3, pp. 71-87. DOI: 10.24411/2686-7206-2020-10304.

7. Shugrina E.S. Osobennosti pravovogo statusa raznyh vidov municipal'nyh obrazovanij [Peculiarities of the Legal Status of Different Types of Municipalities]. Lex Russica, 2017, no. 2 (123), pp. 1725. DOI: 10.17803/1729-5920.2017.123.2.017-025.

8. Typovyj statut terytorial'noi' hromady [A Model Charter of a Territorial Community]. Kyiv, 2020. 68 p. URL: http://auc.org.ua/sites/default/files/ library/modul_1.pdf(accessed 22 April 2021).

9. Davydova M.L., Makarov V.O. Smart Technologies in Lawmaking: Towards the Concept of Smart Regulation. Lecture Notes in Networks and Systems, vol. 155, pp. 1296-1305. DOI: 10.1007/978-3030-59126-7_142.

10. Deslatte A. Municipal Charters. Encyclopedia of Public Administration and Public Policy. Taylor \& Francis Group, 2015. DOI: 10.1081/E-EPAP3120053329.

11. Svara J. Revising the Model City Charter: The Case for Change. National Civic Review, 2020, vol. 109, no. 3, pp. 35-45. URL: https://www.jstor.org/stable/ 10.32543/naticivirevi.109.3.0035 (accessed 22 April 2021).

\section{Information About the Author}

Irina A. Kareva, First Vice-Rector, Volgograd Conservatory (Institute) named after P.A. Serebryakov, Mira St, 5a, 400066 Volgograd, Russian Federation, kareva19@gmail.com, https://orcid.org/0000-0002-0558-9833

\section{Информация об авторе}

Ирина Александровна Карева, первый проректор, Волгоградская консерватория (институт) им. П.А. Серебрякова, ул. Мира, 5a, 400066 г. Волгоград, Российская Федерация, kareva19@gmail.com, https://orcid.org/000-0002-0558-9833 